\title{
Acumulação social da violência e sujeição criminal em Alagoas*
}

Emerson Oliveira do Nascimento**

Resumo: Ao se utilizar dos conceitos de acumulação social da violência e sujeição criminal, o presente texto visa construir uma reflexão acerca das transformações em torno do fenômeno da violência no estado de Alagoas. A partir da compilação de matérias jornalísticas, documentos oficiais e entrevistas com os agentes do sistema de justiça criminal estadual, buscou-se situar historicamente o problema da violência na região. Argumento que ao longo dos últimos 50 anos, dos tradicionais crimes de mando à "institucionalização" dos grupos de extermínio, e destes para o fenômeno da multiplicação desenfreada dos crimes de homicídio no estado, assistiu-se ao acúmulo de formas e práticas de violência diferentes que sedimentaram a constituição de diferentes tipos ditos perigosos. Na contramão das análises que insistem em interpretar a violência de hoje exclusivamente como contiguidade do passado, considero que a explosão de homicídios no estado é um acontecimento peculiar e relativamente recente.

Palavras-chave: acumulação social, sujeição criminal, violência, homicídios, Alagoas.

Em Alagoas, toda família tem um assassino ou um assassinado.

Tenório Cavalcanti.

\section{Apresentação}

A o longo do presente texto, utilizo com especial relevância dois referenciais fundamentais de matriz sociológica. São estes os conceitos de acumulação social da violência e o de sujeição criminal (Misse, 1999). Estes conceitos foram elaborados para problematizar o fenômeno da violência urbana no contexto carioca e há muito já foram incorporados à literatura especializada. Não obstante as especificidades históricas, sociais e culturais marcadamente distintas entre estas regiões, acredito que a importação de tais conceitos para pensar outra realidade pode revelar-se uma estratégia cognitiva interessante. É neste sentido que busco, depois de apresentar estes conceitos, situar historicamente o problema da violência na região Nordeste, em especial no estado de Alagoas, destacando os limites da tese tradicional que têm associado a violência da região, de maneira residual, ao passado agrário, escravocrata e monocultor do estado e reforçado a representação de uma sociedade desde sempre e para sempre violenta.

\author{
* A elaboração \\ deste trabalho não \\ seria possível sem \\ o apoio do CNPq \\ para o projeto \\ de pesquisa de \\ pós-doutoramento \\ sobre a organização \\ social do espaço \\ e a violência letal \\ na cidade de \\ Maceió e Região \\ Metropolitana. Não \\ poderia ainda deixar \\ de registrar aqui meu \\ agradecimento às \\ sugestões valorosas \\ dos comentaristas \\ anônimos da Revista \\ Sociedade e Estado.

\footnotetext{
**Professor/ pesquisador do Programa de Pós-Graduação em Sociologia do Instituto de Ciências Sociais da Universidade Federal de Alagoas. Tem mestrado e doutorado em ciência política pela Universidade Federal de Pernambuco. $<$ emersondo nascimento@yahoo.
} \\ com.br>.
}


1. Desde 2006, segundo dados do Sistema de Informação de Mortalidade do Ministério da Saúde (SIM-MS) e do Fórum Brasileiro de Segurança Pública (FBSP), Alagoas ocupa a posição de estado mais violento do Brasil, liderando o ranking da lista no que compreende a taxa de homicídios.
A ênfase na persistência de um passado, irredutível neste caso, tem contribuído pouco para deslindar o problema do crescimento vertiginoso da violência homicida em Alagoas nos últimos 25 anos. Na contramão dessas tradições, argumento que a compreensão do fenômeno prescinde de um giro epistemológico que nos permita ver as descontinuidades naquilo que nos parece tão somente linear. Em outras palavras: é preciso analisar as transformações significativas em torno dos usos, das práticas e dos sentidos da violência no estado ao longo do tempo a fim de se questionar esta representação de uma sociedade forjada pela e para a violência. Para isso, demarcando Alagoas como cenário privilegiado da expressão da violência na região Nordeste, observo o processo acumulativo de variadas formas de violência no estado, tomando como mote a constituição do sistema de pistolagem a partir da segunda metade do século passado, sua especialização e ramificação em torno dos grupos de extermínio que se formaram entre as décadas de 1980 e 1990 e, em seguida, a escalada de um processo de violência difusa marcado pelo crescimento vertiginoso da taxa de homicídios que lhe renderá a alcunha de capital da morte ${ }^{1}$.

O recorte temporal deste artigo (1950-2000) privilegia a cobertura de acontecimentos diferentes e recentes da sociedade alagoana, todavia, não compreendo com isso a constituição de uma história social da violência no estado ou algo que o valha, muito pelo contrário. A demarcação deste período atenta para o processo recente de modernização social e econômico que tem acompanhado o fenômeno do crescimento da violência urbana no estado. E, em busca de uma interpretação sociológica para estas transformações, começo aqui por discutir a ideia de construção social do crime como preâmbulo para uma breve contextualização do fenômeno da violência no Nordeste, as transformações operadas na subcultura dos crimes de mando e do sistema de pistolagem em Alagoas até a estruturação do chamado Sindicato do Crime. Depois, discuto o processo de transmutação do Sindicato (organização de origens rurais voltada à mercantilização de práticas ilícitas e associada às formas tradicionais de dominação próprias do sertão) para grupos de extermínio como a Gangue Fardada e os Ninjas de União (organizações eminentemente urbanas, paramilitares e profissionalizadas para atender a um estruturado mercado da morte na região). Ao final, discuto o quanto essa variedade de eventos e dramas arquitetados estão longe de representar um todo unificado e linear e, em se tratando do fenômeno da violência urbana no estado de Alagoas, o quanto as explicações historicistas para o fenômeno têm dificultado a percepção em torno das transformações da prática da violência na região e restringido a reflexão sobre vias possíveis para a superação do problema.

O presente artigo fundamenta-se ainda em pesquisa documental apoiada sobre diversas fontes, desde notícias veiculadas nos jornais e semanários de Alagoas no 
período compreendido pela pesquisa - Desafio, O Jornal de Alagoas, Gazeta de Alagoas e Tribuna de Alagoas -, até atas e documentos do Fórum Permanente Contra a Violência em Alagoas e o Relatório Final da Comissão Parlamentar de Inquérito da Câmara dos Deputados que investigou crimes de pistolagem no Nordeste, ainda no final dos anos 1990. No mais, foram utilizadas também entrevistas com agentes do sistema de justiça criminal estadual, bem como os depoimentos de pistoleiros e matadores, consultados através dos inquéritos já julgados ou arquivados junto ao Ministério Público do Estado de Alagoas.

\section{A construção social do crime}

Apesar de consolidada a transição para o regime democrático entre nós, a violência persiste e em proporções crescentes no seio da sociedade brasileira. Para além do que falam os analistas que insistem na ideia de um país cindido entre o mundo legal e um mundo real, melhor seria - parafraseando Machado da Silva $(1995,1999)$ substituirmos a metáfora das duas lógicas que se contrapõem pela imagem, mais complexa, das lógicas que coexistem: a ordem institucional-legal e a violência urbana. Perspectivas como esta são frutíferas do ponto de vista analítico na medida em que buscam compreender o fenômeno da chamada violência urbana per se e não a partir das expectativas de universalização da ordem legal. A permanência do fenômeno da violência urbana entre nós supera as hipóteses de que esta seria tão somente um produto da incompletude do processo de modernização e normalização da sociedade brasileira e, não por acaso, as soluções provisórias que apostavam para o controle da violência a partir da expansão do império da lei encontram cada vez menos parâmetros de confirmação.

Na trilha do que afirma Machado da Silva, embora a ordem institucional-legal padeça de uma crise de legitimidade entre nós, ela está longe de significar uma deslegitimação da ordem constituída. Nesse sentido, a coexistência destas duas ordens chama a atenção para a novidade em torno das práticas da violência na sociedade brasileira contemporânea: não tratamos aqui simplesmente de um complexo de condutas contra o Estado, dentro do Estado ou a partir do Estado, mas da emergência de um parâmetro de sociabilidade cuja ordem pública não entra como referência. Tratar-se-ia do surgimento de uma forma de sociabilidade radicalmente nova, intitulada pelo autor de sociabilidade violenta ${ }^{2}$. Esta perspectiva inaugura uma agenda nova para os estudos sobre a violência urbana no Brasil, que passa a ser vista não como fim, mas como ponto de partida das análises dos cientistas sociais.

Dentre as tradições inauguradas no âmbito da sociologia da violência que partem desta autonomização do mundo social, destacamos aqui as reflexões misseanas.

2. Luiz Machado da Silva (1995) defende a ideia da emergência no Brasil de uma nova forma de sociabilidade, marcadamente violenta, que não se orienta pela alteridade ou pela subjetividade compartilhada e que traz à tona um novo tipo de individualismo que admite e coexistência, entre outras formas, de sociabilidade (pré-modernas e modernas) e com a própria ordem institucional-legal. Não se trata mais da tradicional discussão sobre a violência relacionada à "ausência do Estado" ou à "violência do Estado", nem mesmo a ideia da violência que promove o "Estado dentro do Estado", mas a percepção de que a violência está relativamente organizada dentro de um novo padrão de sociabilidade que coexiste "harmonicamente" dentro do ordenamento legítimo. 
Michel Misse confecciona conceitos relevantes para pensar as transformações recentes em torno do fenômeno da violência urbana, a saber, as ideias de acumulação social da violência e sujeição criminal. Criados em princípio para pensar a organização social da violência carioca, os conceitos misseanos entronizam uma perspectiva analítica diferenciada para a compreensão do problema. O autor propõe que compreendamos o fantasma social do crime que hoje assola nossas metrópoles através do ponto de vista de um processo cíclico e dinâmico de acumulação social de práticas e formas diferentes de violência, a partir do qual seria possível observarmos não apenas as continuidades, mas ainda a intermitência dessas práticas ao longo do tempo e sobre os padrões de sociabilidade e incriminação em uma dada comunidade.

O autor não argumenta que haja uma ruptura radical entre a criminalidade anterior à década de 1980, produzida notadamente no Rio de Janeiro, e a criminalidade mais recente, mas aponta para a existência de uma acumulação cíclica de padrões, experiências sociais e continuidades "subculturais" a partir das quais explica a amplitude do fenômeno. Trata-se de uma argumentação não linear e não evolucionista, preocupada em demonstrar menos o "aumento da violência urbana" e mais a "acumulação social de padrões diferentes de sociabilidade" (Misse, 1999). A título de exercício analítico, o modelo desenvolvido pelo autor distingue as práticas qualificadas como violentas do universo das representações sociais destas diferentes práticas, tentando demonstrar que o fenômeno da violência urbana é socialmente construído, tanto pelas práticas violentas, quanto pelo acúmulo das representações sobre estas ao longo do tempo.

Ao tecer uma teia complexa que vai das práticas às representações e vice-versa, Misse busca, no caso carioca, detectar os principais momentos de fabricação desse grande fantasma social que se tornou o fenômeno da violência urbana. Contudo, o autor não nega a emergência do fenômeno na agenda pública, ainda que não seja este seu objetivo. Muito menos, rejeita a dimensão do problema. Sua proposta é tratar, também sob uma perspectiva sociológica, a percepção e o significado do "aumento da violência urbana". É importante dizer ainda que o conceito misseano de acumulação social da violência não pode ser entendido também como memória social da violência, pois se trata de algo bem distinto. O conceito elaborado pelo autor não se restringe a apinhar reminiscências ou tão somente narrar ou descrever o conteúdo de práticas violentas através do tempo, mas sim, a partir de uma perspectiva dinâmica, lançar uma lupa sobre um fenômeno complexo que relaciona práticas criminais, segurança pública, transformações na esfera da sociabilidade urbana recente e a emergência do medo social e da ideia da chamada "cidade perigosa". 
A noção de acumulação social da violência abdica de operar com um conceito de violência, por compreender que existem várias interpretações da violência e tal multiplicidade não pode ser encapsulada numa representação ou definição uníssona, e prefere, em seu lugar, tomar como referência a representação da própria violência, seu perigo, sua negatividade social, seu risco e sua abrangência e diferenciação sobre os mais diferentes tipos sociais, sobre os centros urbanos, sobre as dinâmicas de sociabilidade que acompanham tal representação e até mesmo sobre os diferentes receituários acerca de como destruí-la ${ }^{3}$. O autor irá afirmar ainda que no imaginário social que acompanha esse processo, os sujeitos sociais considerados "desviantes" que circulam entre esse mundo de representações, práticas, polícias e sistema judiciário são atores privilegiados de um segundo fenômeno igualmente importante e diretamente associado à chamada acumulação social da violência: a sujeição criminal.

O universo das representações sociais sobre a violência urbana demarcará as pessoas que circulam nesse submundo e as demais, sugerindo uma especialização da expectativa sobre um certo tipo de experiência social - as dinâmicas de rotulação dos sujeitos antecipadamente acusáveis. A partir dos estudos pioneiros sobre as noções de desvio (Merton, 1969), estigma (Goffman, 1988) e divergência (Becker, 2008), Misse subsidiará sua noção de sujeição criminal como elemento nuclear da compreensão de um processo longo de normalização no Brasil e, especialmente, no Rio de Janeiro, dos tipos ditos potencialmente perigosos. Para isso, o autor irá partir das cadeias de acusação social que interligam de forma cumulativa, mas não linear, diferentes comportamentos e unidades-objetos de acusação ao longo do tempo e chamará nossa atenção para aquele que seria, talvez, o maior efeito perverso da acumulação social da violência no Rio de Janeiro: a substituição da referência à norma pela referência ao risco. Em outras palavras: a substituição da força da lei como parâmetro para avaliar a transgressão ou a divergência, em favor de um modelo complexo de punibilidade, onde indivíduos condenados serão demarcados sob a expectativa de que são e continuarão a ser regularmente transgressores. O chamado processo de sujeição criminal de que trata Misse aponta não somente para uma rotulagem ou uma designação de incriminação regular de certos tipos de práticas, mas para a constituição de subjetividades que incriminam tipos sociais que serão, antes de qualquer coisa, incriminados por que "eles são eles", naturalmente, definidos como "seres criminais" (Misse, 1999: 50, 52-53, 59).

Há um número farto de estudos que apontam para o longo processo de desenvolvimento da disciplina, da norma e da civilidade na sociedade ocidental. Neste processo, vários atores pontam para a ambiguidade do individualismo moderno, capaz de erigir os meios de administração legítima da justiça pelo Estado moderno através da
3. Diferentemente de outras perspectivas que consideram o universo da representação social da violência a partir da percepção que o fenômeno imprime sobre os agentes sociais, a perspectiva misseana toma a representação como parte constituinte do próprio objeto. Neste sentido, o esforço analítico proposto pelo autor assume os riscos e rompe o distanciamento metodológico entre a norma que criminaliza e a representação social normalizadora, buscando superar a dicotomia entre a dimensão ideológica do objeto e sua construção social. Nesse sentido, a partir da ideia de acumulação social da violência, o autor supera ontologias utópicas normalizadoras do fenômeno do crime e epistemologias exíguas que dão rosto e forma à prática da violência, mas desconsideram o processo social de criminaçãoincriminação. 
tipificação de ações ditas criminalizáveis e, simultaneamente, "deslocar" a acusação da transgressão para o transgressor, do ato do sujeito, para a subjetividade do sujeito. Foi Foucault em sua genealogia das formas de punir que chamou tal processo de "passagem da lei à norma" (Foucault, 1974; 1977), quando desaparecem as gradações clássicas que referenciam a processualística que integra a subsunção da lei ao fato, e a acusação recai não sobre o ato, mas sobre o próprio sujeito, sobre a sua natureza. Quando a lei impera, não é o sujeito que é punido, mas a sua transgressão. Quando ocorre o oposto - quando a norma impera -, é o próprio sujeito que é questionado. A acusação especializa-se em reafirmar a personalidade transgressora do sujeito.

É sabido que a naturalidade de uma teoria não imprime limites territoriais ao seu poder heurístico, bem como, pouco podemos fazer contra os usos e abusos de uma teoria mundo afora. Contudo, em se tratado do fenômeno da violência urbana, a dita "naturalidade" da teoria aqui em questão estende-se sobre a própria elaboração do nosso objeto, tendo em vista que o Rio de Janeiro se tornou também, por muito tempo, o recorte através do qual o brasileiro médio, morador das grandes cidades brasileiras, construiria sua percepção sobre o fenômeno da violência urbana. A própria presença do Rio de Janeiro na pauta quase cotidiana da mídia escrita e televisiva quanto ao "aumento da violência urbana" recicla e exporta representações sociais da insegurança, do perigo social e do medo urbano para outras capitais e regiões, indistintamente. A ideia da violência como onda fantasmagórica que se estende do eixo Rio-São Paulo para as demais regiões do país, com ênfase agora para os estados nordestinos, é tão inconsistente quanto a ideia de uma cultura da violência que permanece restrita e circunscrita à região Nordeste, especialmente ao estado de Alagoas, popularmente conhecido como o mais violento do país. Na seção seguinte, discuto o que há de permanente e de novo no crescimento vertiginoso da violência no Nordeste nas últimas décadas, sobretudo em Alagoas.

\section{Alagoas, terra de antropofagia?}

Quando o historiador gaúcho Décio Freitas chamou Alagoas de "Sicília brasileira" estava coroando com uma máxima altissonante algo há muito já arraigado no senso comum dos alagoanos e dos observadores externos - a ideia de que o estado de Alagoas, sua história, seus valores culturais e políticos foram talhados sob o jugo da violência e assim permaneceria. Esse credo engrossou o caldo lamurioso que entroniza Alagoas como uma espécie de bastião do atraso nacional, marcadamente uma terra sem lei, corrupta e, por isso mesmo, violenta. O fenômeno da violência é apreciado sob este prisma como um acontecimento em cadeia, progressivo e evolutivo. A violência dos dias atuais seria o produto residual do passado colonial e depois, do 
clientelismo, do mandonismo e do coronelismo, que teriam sequestrado a própria estrutura do Estado em prol do benefício privado e estabelecido a violência como base definidora das relações sociais na região.

Essa busca por uma continuidade linear entre as formas da violência praticadas no passado e as conformações que o fenômeno da violência veio assumindo ao longo do tempo na região é tentadora. É necessário, contudo, afirmar que há evidentes diferenças quanto aos distintos tipos desta violência. Aqueles que investem numa "memória social" ou numa "linha de continuidade" na prática da violência na região são indiferentes às mudanças econômicas, geracionais e demográficas, à mobilidade geográfica e social dos grupos, às transformações em torno das formas e das condições de habitação (sobretudo da capital, Maceió) e às grandes transformações ocorridas no estado durante o último quartel do século XX. Os defensores desta tese reforçam a ideia de uma "violência fundante", de um continuísmo "histórico", aspirante à condição de "tradição", onde a violência, ora configura-se como matriz de significado objetivo a partir da qual é possível traçar uma linha de continuidade, ora uma espécie de sistema subjetivo transmissível, internalizado e durável de socialização que admite a perseverança e a sobrevivência de um modus operandi violento por parte do alagoano. Tais perspectivas, ao seu modo, comungam de um resultado comum: concatenam eventos independentes numa mesma direção mediante a assimilação e a apropriação ex post de fatos em favor de uma historicidade funcional cuja "tradição" pretende afirmar e reforçar a imagem de uma sociedade violenta.

A ideia de uma Alagoas antropofágica - em explícita alusão à morte do bispo Sardinha -, devorado em 1556 num ritual de antropofagia ao sul do litoral alagoano pelos índios caetés e, depois, a imagem fragmentária de uma terra carente de normalização cobre não somente o imaginário popular nativo, mas também modela o olhar externo sobre o estado de Alagoas, associado de modo atemporal aos signos de uma modernidade fracassada ${ }^{4}$. Ao contrário do que se observa no caso do banditismo urbano carioca, onde a cidade é retratada, em princípio, como pacífica em relação a uma violência de tipo conjuntural que, no jargão popular somente "cresce e piora"; no caso nordestino, sobretudo em Alagoas, a imagem evocada tem sido a de um território desde sempre violento ${ }^{5}$.

O fenômeno da violência urbana em Alagoas é, naturalmente, distinto de sua expressão em outras cidades ao redor do mundo. Contudo, este argumento não reforça a impropriedade da importação de modelos teóricos para pensar a realidade local, tomando como expoente o caso alagoano e a necessidade de problematizar inside o crescimento da violência no Nordeste. A despeito do fato de que durante as décadas de 1980 e 1990 a maior parte da atenção da academia se voltou para

4. A dramatização estética dos territórios da pobreza, em geral, reserva espaço ao estado de Alagoas, sempre retratado como território carregado de simbologias e antíteses (a terra e o mar, a opulência da zona litorânea e a miséria do sertão), uma espécie de antítese do Brasil ideal, o exemplar de um "outro" Brasil - um espaço marcado pelo atraso e pelo autoritarismo, a reserva de uma tradição que se quer genuína, mas, ao mesmo tempo, carente de superação. Boa parte desse emaranhado de representações do estado deita raízes na literatura regionalista da década de 1930 e na lente do Cinema Novo da década de 1960, que transformou o sertanejo sobretudo o alagoano, fartamente retratado na prosa graciliana celebrada pelos ideólogos cinemanovistas - em sujeitos ignorantes e despolitizados, por um lado, e em rebeldes primitivos e revolucionários, capazes de mudanças radicais, por outro (Albuquerque, 1999).

5. Enquanto no Rio de Janeiro predomina a ideia de uma violência que se incrementa com o passar do tempo, em Alagoas, a violência é representada como um marco originário 
e fundacional da sociedade alagoana.

Ao seu modo,

num e noutro

caso, a despeito

das perspectivas

distintas, seja

no Rio, seja em

Alagoas, ambas as

narrativas convergem

para uma direção

comum: um fundo

mítico partilhado,

onde o fenômeno

da violência é

apropriado e

redimensionado

como matriz

genealógica (Misse,

1999).

6. Há de se destacar

as inúmeras

leituras produzidas

pela tradição

historiográfica e

socioantropológica

sobre o cangaço e

o banditismo rural

nordestino - das

mais simplistas às

mais complexas.

Dentre as primeiras,

das interpretações

mais tradicionais,

destacam-se os

textos de José

Honório Rodrigues

(1965) e Cristina

Mata Machado

(1973) - ambos de

retórica marxista

- compreendendo

o cangaço como

simples "resposta

contra o monopólio

da terra e a

exploração do

trabalhador rural

pelo latifundiário"

ou "uma resposta

à violência do

coronel". Dentre

as interpretações

menos simplistas do

cangaço destacam-

se os trabalhos

de Frederico

Pernambucano de

Mello (2011), o

qual tem chamando

a atenção para o problema da violência urbana no eixo Rio-São Paulo, em virtude das cifras que a violência homicida atingiu nesta região, há de se destacar o número reduzido de esforços voltados para o estudo do fenômeno da violência nas capitais nordestinas - associado de forma abreviada ao signo do atraso e do agravamento da incompletude do processo de normalização burguesa - julgado inconcluso no Brasil - sobretudo nos estados do Nordeste.

A exportação do malandro como tipo mais geral não encontra similaridade no contexto alagoano, ou mesmo nordestino. No Rio, entre 1920 e 1940, encontramos a fixação literária e ideológica do malandro, carregando de sentido o imaginário popular em torno do sujeito capaz de dissolver os extremos, de maquiar o significado da lei e habitar ambiguamente o império da norma e o mundo do crime. Em contrapartida, neste mesmo período, no Nordeste, lapida-se a imagem do sujeito violento por força das intempéries da vida ou das oportunidades - a figura do cangaceiro ${ }^{6}$, personagem histórico do banditismo rural do Nordeste, típico do cenário sertanejo, uma zona fisiográfica perfeitamente definida em termos de contornos naturais e sociais; culturalmente marcada pelo arcaísmo, próprio de uma mentalidade quinhentista que sobreviveu graças ao isolamento e à incomunicabilidade da região que marcariam os padrões de sociabilidade, religiosidade, moralidade, sexualidade e as formas de resolução de conflitos entre as partes como fartamente retratados nas novelas paracervantistas de Franklin Távora, José Lins do Rego, Jorge Amado, Rachel de Queiroz e Ariano Suassuna, onde as culturas tradicionais do sertão - ou melhor seria falarmos em "sertões" - figuram ora como retrato paradoxal de um país selvagem e culturalmente negativo, ora como cenário de um primitivismo precioso e desejável.

A violência urbana na região nordestina - a despeito de esta ser uma área de colonização antiga - é relativamente recente. Tão recente que só muito tardiamente as capitais nordestinas insurgem como objeto para os pesquisadores e não por acaso, pois este crescimento deu-se apenas a partir do final da década de 1990, quando a taxa de homicídios da região saltou de 15 para 35 homicídios por 100 mil habitantes, experimentando um crescimento superior a 100\% entre 1999 e 2010. O crescimento da incidência de homicídios em ritmo acelerado nas regiões Norte e Nordeste, e nas regiões Centro-Oeste e Sul, ainda que em patamares mais modestos, veio acrescido de uma redução expressiva deste percentual na região Sudeste, com destaque para São Paulo, Rio de Janeiro e Minas Gerais, que apresentaram acentuada redução da incidência de homicídios na última década.

Segundo dados do Anuário brasileiro de segurança pública do Fórum Brasileiro de Segurança Pública, constatamos que entre os cinco estados com as maiores taxas de homicídio no ano de 2014, quatro pertencem ao Nordeste do Brasil, quais se- 
jam: Alagoas, Ceará, Rio Grande do Norte, Sergipe, e um ao Norte, o Pará. O mesmo fenômeno é observado nas capitais brasileiras, destacando-se Maceió, Fortaleza, Natal, Aracaju e Belém ${ }^{7}$. Em seu conjunto, estes dados apontam para uma mudança significativa na dinâmica espacial do fenômeno das mortes violentas na sociedade brasileira. Se na década de 1990 a região Sudeste concentrou boa parte do crescimento da violência urbana, sobretudo no Rio de Janeiro e São Paulo, passadas duas décadas, são os estados nordestinos que passam a encabeçar o ranking dos estados mais violentos da Federação8.

Ao considerar o fenômeno da violência como não igualitário, tendo em vista que é notoriamente conhecido que as vítimas de homicídio no Brasil apresentam um perfil básico - homens, jovens, pobres e negros -, é cada vez mais necessário considerarmos também a dinâmica espacial do fenômeno dentro do território nacional. Enfocar o problema dos territórios e sua relação com o fenômeno da violência urbana significa entender as cidades e as regiões como ecossistemas cuja diversidade e interdependência cumprem a função de revitalização e controle das pessoas que habitam estes espaços ${ }^{9}$. Compreender que processos físicos, econômicos e éticos afetam a segurança e interferem diretamente nos mecanismos habituais de controle das cidades é fundamental para compreender a dinâmica das ondas e marolas de insegurança, risco e medo que têm atingido as capitais e regiões metropolitanas brasileiras nas últimas décadas ${ }^{10}$.

Desde de 1999, a violência homicida tem crescido no estado de Alagoas, com especial destaque para Maceió e Região Metropolitana, de forma ininterrupta. Em 1999, a taxa de homicídios no estado era de 30,9 para cada 100 mil habitantes. Em 2010, essa taxa chegou a 66,8 homicídios para cada 100 mil habitantes. Apesar de alarmantes, estes dados são relativamente novos, visto que desde 1980 esta taxa situava-se no patamar de 25 homicídios por 100 mil habitantes, em nada destoando com a média regional ${ }^{11}$. Não obstante, segundo dados do Sistema de Informação de Mortalidade do Ministério da Saúde, nas últimas três décadas, o número de homicídios em Alagoas cresceu mais de $420 \%$. Somente nos últimos cinco anos, entre 2010 e 2014, ocorreram 10.713 homicídios em Alagoas, 87\% destes concentrados na capital do estado e em sua Região Metropolitana ${ }^{12}$.

Nas últimas três décadas, a população urbana de Alagoas saltou de 600 mil para dois milhões de habitantes, trazendo junto com esse crescimento demográfico todos os problemas próprios da urbanização desenfreada. Este processo não veio acompanhado da atração de novas oportunidades de trabalho ou de novas empresas, mas somente do aumento estrondoso da população urbana, sobretudo da capital do estado e das cidades que compõem sua Região Metropolitana. Esse quadro das a pluralidade e a diversidade do cangaço, destacando a ausência de uniformidades causais de qualquer natureza para o fenômeno, sejam elas psicossociais, ecológicas, econômicas ou políticas.

7. Dados do Anuário brasileiro de segurança pública para percentuais de homicídios dolosos, por número de vítimas e ocorrências no Brasil e Unidades da Federação, entre os anos 2013-2014 (Fórum Brasileiro de Segurança Pública, 2015).

8. Há de se destacar aqui que o estado de Pernambuco se configura como exceção no contexto do crescimento da violência homicida na região Nordeste; trata-se do único estado que vem apresentando taxas de homicídios decrescentes, a saber: 35,7 mortes por 100 mil habitantes para o ano de 2014 (Sapori \& Soares, 2014).

9. Para a chamada teoria da desorganização social, as comunidades urbanas são complexos sistemas de redes de associação formais e informais, cuja estrutura de oportunidades pode favorecer positivamente ou negativamente a ocorrência de 
diversas formas de delitos. Numa perspectiva menos ortodoxa, as cidades são o palco das redes de relações que ali se estabelecem, incentivando ou não, sob diversas formas, o crime violento e a capacidade de autorregulação dos sujeitos (Sampson et alii, 1997).

10. Uma das principais formas de realizar esta relação é examinar as taxas de criminalidade agregadas em áreas geográficas que buscam explicar variações de taxas de crime violento entre várias cidades, áreas metropolitanas, estados ou mesmo países (Beato, 2012 : 146-147).

\section{1. É incorreto} ainda afirmar que Alagoas seja o líder em violência letal quando consideradas outras taxas de mortalidade como os suicídios e os acidentes de trânsito (nestes aspectos, Alagoas apresenta taxas idênticas às de outros estados do Brasil). Em Alagoas, apenas os índices envolvendo homicídios destacamse da média brasileira (Nascimento \& Gaudêncio, 2013).

12. Em junho de 2012, a condição alarmante das taxas de homicídio em Alagoas induziu o governo federal e o Ministério da Justiça a escolher como piloto o estado para experimentar a dificuldades locais justificou grandes ondas de mobilidade das zonas rurais para as áreas urbana, bem como das cidades do interior para a capital, sobretudo depois do fechamento das fronteiras de expansão econômica e dos mercados de trabalho do Sudeste. $\mathrm{O}$ antigo movimento migratório da pobreza da região para outros estados em busca de melhores condições de vida acabou sendo, aos poucos, suplantado por um movimento maciço de deslocamento dentro do próprio estado (Carvalho, 2012). A dificuldade que o estado tem encontrado nas últimas três décadas para diversificar sua atividade produtiva ${ }^{13}$, a despeito da chegada relativamente recente de novas indústrias no setor químico e de plásticos, é um indicador da involução econômica que o estado tem sofrido, percebido pela baixa dinamização do mercado de trabalho e pela dificuldade de superação de indicadores sociais negativos que atinge, hoje, pelo menos, dois terços da população alagoana. E é esta parcela excedente da população, excluída da rede de economia informal, que predomina nos bairros populares da capital e das cidades do interior, população marginalizada, a ocupar e povoar os atuais 300 aglomerados insólitos da capital.

No caso alagoano, a população exibe um perfil de renda extremamente desigual, com significativa parcela sem acesso a bens sociais básicos. A segmentação social e a distribuição desigual da riqueza entre o $1 \%$ dos mais ricos (30 mil pessoas) com $12,82 \%$ da renda per capita e os outros $50 \%$ mais pobres (1,5 milhão de pessoas) com apenas $14,29 \%$, chamam a atenção para a assimetria na distribuição da riqueza dentro do estado ${ }^{14}$. E esta má distribuição teria ainda outra face pouco destacada. De acordo com dados do Instituto Brasileiro de Geografia e Estatística para o ano de 2010, a maioria da população pobre de Alagoas é constituída maciçamente por negros ou pardos. Não bastasse, o nível educacional também reforça a forte concentração de renda deste mercado interno - segundo dados da Pnad para o ano de 2015, enquanto a escolaridade média da população de 18 a 29 anos de idade no Nordeste gira em torno de 9,3 anos, em Alagoas temos a menor média em anos de estudo por unidade da federação, a saber: 8,7. Ainda em Alagoas esse déficit torna-se ainda mais alarmante quando consideramos os marcadores étnicos desta população - enquanto para a população branca temos a média escolar de dez anos de estudo em 2015, para a população preta e parda temos, respectivamente, 8,4 e 8,3 anos de estudo (Ministério da Educação, 2017). As consequências dessa combinação de apartheid social, alta concentração de renda, baixa escolarização e urbanização acelerada delinearam, nos últimos 50 anos, a base para a explosão dos homicídios que assistiríamos na capital a partir da virada do novo século.

É preciso analisar o complexo emaranhado desses fatores e destacar o processo de constituição de uma espécie de circularidade cumulativa da violência no estado. 0 interesse aqui não é explicar ou compreender as adesões individuais a cursos de 
ação crimináveis, mas contribuir para a compreensão de um processo social complexo - a condensação da violência na região. Em outras palavras: de que forma cursos de ação (estratégias de sobrevivência, estratégias aquisitivas, modos de operar o poder, status e identidades em condições subalternas), no bojo destas transformações sociais, se relacionaram de forma cumulativa, dinâmica e não linear em Alagoas, criando as condições necessárias para a constituição de um estágio anômalo de descontrole dos percentuais de violência homicida no estado a partir da primeira década do novo século? Observarei adiante as mutações em torno das práticas criminais tradicionais do estado (os crimes de mando, o sistema de pistolagem e a arregimentação de grupos de extermínio) e seu impacto sobre a constituição de sujeitos criminais ${ }^{15}$.

\section{Matar e morrer em terras alagoanas}

Na contramão dos argumentos que reforçam a antiguidade do fenômeno da violência em Alagoas, acredito que há nítidas distinções entre as práticas de violência próprias do passado e o que chamo de novas práticas de violência. Não quero com isso desconsiderar a importância da trajetória sócio-histórica do estado, mas demarcar os limites entre as tradicionais práticas de violência do passado e o incremento de uma indústria da morte que se desenvolveu em Alagoas a partir do final da década de 1990. É fato que a história alagoana é entrecortada por acontecimentos que demonstram o quanto a violência foi utilizada fartamente pelas elites oligárquicas, muitas vezes com a participação direta do Estado, para manutenção e preservação do status quo. Conquanto, argumento que tomar a violência atual como resíduo ou mera expressão de um passado, impede-nos de enxergar a novidade radical do problema: o crescimento vertiginoso de um tipo específico de violência - a homicida - e em proporções nunca dantes experimentadas.

A fim de tentar entender o lugar que ocupam os conflitos, especialmente os homicídios na sociedade alagoana atual, é preciso compreender como se dá o processo de difusão e irradiação da violência no estado. Acredito que para percebermos a tolerância que se desenvolveu para com a prática recorrente da violência no estado, é necessário observarmos os mecanismos através dos quais os homicídios do passado (praticados pelos grandes proprietários de terra e pelos políticos contra seus opositores como apanágio ou atributo de seus poderes de mando) foram objeto de uma complacência perniciosa para com os conflitos caracterizados por desenlaces hediondos, sobretudo nas grotas e periferias da cidade de Maceió. Nestes cenários, a ausência de um monopólio regular da violência física (não existe a concentração de armas e homens armados sob uma única autoridade, seja ela o Estado ou o crime organizado) tornou o autocontrole tênue (Elias, 1993) e transformou o medo, a eficácia do Programa Brasil Mais Seguro. O programa integra o Plano Nacional de Segurança Pública no Ministério da Justiça e tem por objetivo induzir e promover a atuação qualificada e eficiente dos órgãos de segurança pública e do sistema de justiça criminal, focando na qualificação dos procedimentos investigativos e na maior cooperação e articulação entre as instituições de segurança pública e o Sistema de Justiça Criminal Poder Judiciário e Ministério Público.

13. Ao longo da década de 2000, o Produto Interno Bruto de Alagoas cresceu de modo inferior às economias de outros estados ditos mais pobres, como o Piauí e o Maranhão. Este desenvolvimento mais lento, sobretudo quando comparado a outros estados da região, levou alguns analistas a apostarem na tese de uma "involução relativa" da economia alagoana, o que tem sido reforçado pela baixa capacidade de o estado responder economicamente aos desafios de reversão deste cenário, bem como pela dificuldade de reversão dos indicadores sociais negativos há muito persistentes no contexto da sociedade alagoana (Gomes, 2011; Carvalho, 2000). 
14. De acordo com estudo realizado pelo Instituto Brasileiro de Geografia e Estatística para ano de 2010, Alagoas ocupa a posição de estado mais desigual do país (IBGE, 2010).

15. A defesa pela compreensão dos processos locais de sujeição criminal não significa uma disjunção entre a ideia de demanda legal de incriminação, própria da justiça racional-legal, formal e processual, e a transgressão propriamente dita. De acordo com Misse, o processo de incriminação é mais complexo do que identificar, denunciar ou prender indivíduos - não se incriminam transgressões, mas indivíduos. 0 conceito de sujeição criminal não se sobrepõe ao fato ou à lei, mas analisa sua realização legal, destacando que nem só de códigos faz-se a incriminação de um indivíduo, mas através de um processo social de constituição de subjetividades, identidades e subculturas que participam da constituição do sujeito dito "criminoso" (Misse, 1999). precaução e a autodefesa na tônica de uma explosão de violência autofágica, onde vítima e algoz muito se assemelham em termos de sexo, cor/raça, idade, renda e até mesmo anos de escolaridade.

Da morte sob encomenda - típica da segunda metade do século passado - à sensação generalizada da guerra de todos contra todos - dos dias de hoje - é preciso investigar os sentidos desta transformação. Num primeiro momento, foram os capangas e jagunços, os tipos lendários da sociedade brasileira, especialmente nordestina e alagoana, que, sob a proteção e as benesses dos grandes proprietários de terras, combinavam as atividades regulares do campo com a prestação de "favores ilegais" aos seus patrões, sempre orientados por princípios mais morais do que pecuniários. Numa região fortemente marcada pela presença da economia da cana-de-açúcar, estes tipos andavam "à tira colo" dos chamados "coronéis", fazendeiros e senhores de terras, símbolos da onipotência e da impunidade que caracterizaram o mundo rural brasileiro desde o final do século XIX. Em Alagoas, os capangas e jagunços foram, até a primeira metade do século passado, o "braço armado" da economia canavieira, responsáveis por eliminar aqueles que contrariassem os interesses de seus protetores.

A partir da década de 1950, as transformações advindas do processo de urbanização ao longo da primeira metade do século XX e as novas relações estabelecidas pelo agronegócio a partir da década de 1970, trouxeram também transformações na esfera da administração dos conflitos sociais em Alagoas. A fidelidade, a valentia e a astúcia dos antigos capangas e jagunços cedeu espaço à profissionalização dos chamados matadores de aluguel ou tão somente pistoleiros, estes, não mais serviçais dos grandes proprietários rurais, mas prestadores de serviço para usineiros e quadros políticos profissionais. A estruturação do chamado sistema de pistolagem no Nordeste constituiu-se em complexa engrenagem, recheada de normas próprias. Para compreender esse sistema, devemos compreender, primeiro, o impacto das transformações sobre a base da dominação tradicional das elites políticas e econômicas no sertão nordestino (Barreira, 1992; 1998).

Ameaçadas pelas transformações advindas mediante a reformulação das relações entre campo e cidade, o sistema de pistolagem tornou-se o recurso que as novas elites usariam de maneira farta para garantir a consecução dos seus interesses. 0 sistema de pistolagem, portanto, caracterizou-se pela constituição de uma rede sofisticada de proteção, a qual incluía não somente os favores dos usineiros e políticos profissionais, mas também o apoio do próprio sistema de justiça criminal. Se antes capangas e jagunços comportavam-se quase como extensão física de seus senhores, os pistoleiros caracterizavam-se agora como anônimos, profissionais, que, sem maiores vínculos morais, ofereciam seus "serviços" a quem retribuísse o valor exi- 
gido pela execução da tarefa ${ }^{16}$. Em regra, os crimes de pistolagem eram sempre direcionados a um opositor, um alvo político com identidade muito bem definida, que deveria ser eliminado fisicamente por ter se envolvido em disputas contra políticos ou usineiros. O pistoleiro e o mandante contavam ainda com uma terceira peça que dava movimento à toda engrenagem: o intermediário. Os pistoleiros possuíam astúcia e os mandantes dinheiro, mas a negociação era coordenada pelo intermediário que, de fato, fazia a roda rodar. A presença do intermediário - o corretor da morte - demarca o momento desta institucionalização do sistema de pistolagem e o processo de estruturação de uma rede complexa de hierarquias e diferenciação de papéis entre as partes.

Os primeiros registros de um sistema organizado e profissionalizado dos serviços de pistolagem em Alagoas datam de meados da década de 1950 e encontram sua institucionalização no chamado Sindicato do Crime - quando capangas e jagunços deixaram a proteção de seus "padrinhos" e passaram a tutelar suas próprias carreiras criminais, firmando-se cada vez mais a partir de contornos impessoais e profissionais. Esta quadrilha de pistoleiros de aluguel, uma dentre tantas outras que se propagaram pelo Nordeste neste mesmo período, lançou as bases para a constituição de um mercado informal de práticas criminosas no estado de Alagoas. As relações de poder que se reproduziram a partir do Sindicato do Crime não eram resultado somente de um Estado "impotente", mas, sobretudo, da afirmação de um poder paralelo, que fez coexistir, simultaneamente, modernidade e arcaísmo, o universalismo do código jurídico e o caráter privatista de seus próprios códigos e regras morais, a justiça legal e a justiça praticada com as próprias mãos. Aos poucos, capangas e jagunços deixavam de ser que executores de "serviços" em troca da proteção dos proprietários rurais e tornavam-se pistoleiros, profissionais independentes que exigiam recompensa financeira por seu "trabalho" e se beneficiavam da própria "institucionalização da violência" - a proteção do chamado Sindicato do Crime.

\section{Grupos de extermínio e o mercado da morte em Alagoas}

O mercado da morte ${ }^{17}$ tornou-se, nos idos da década de 1980, uma esfera promissora de oferta de serviços de pistolagem e práticas ilícitas que transformaria os modelos de sociabilidade da sociedade alagoana e do seu entorno. Mesmo para os padrões nordestinos, há muito familiarizados com os crimes tradicionais de morte "encomendada", a constituição de um mercado organizado de oferta e procura por serviços de assassinato profissional, com direito a preços tabelados, representou uma transformação significativa nos padrões da violência tradicional da região. Ao longo desta seção busco dar continuidade à análise desse processo de sedimenta-
16. 0

profissionalismo

dos pistoleiros

é fartamente

registrado no

universo de causos,

contos e anedotas

nordestinas. Numa

dessas anedota, em

que se confunde o

ocorrido e o narrado,

o diálogo entre um

curioso e um temido

pistoleiro é assim

reconstituído:

- Você teria

coragem de

matar um filho de

Deus sem motivo

nenhum?

- Coragem eu não

tenho não, o que eu

tenho é costume.

17. A alusão aqui

à ideia de um

"mercado da morte" parte da ideia inicial de Misse (1999)

de constituição de um mercado ilícito de "mercadorias políticas" específicas como possibilidade criada a partir da ambivalência de uma ordem racionallegal instituída (incriminação) que se quer universal e uma ordem paralela clandestina, ilegal e particularista (acusação), que transforma agentes da lei e transgressores em negociantes, onde tudo tem um "preço" - da extorsão ao homicídio. 
18. Em Alagoas, o Relatório final da CPI da pistolagem no Nordeste apontou o envolvimento direto de policiais no sistema dos grupos de extermínio. Eles participavam, ao mesmo tempo, como agenciadores e matadores: "No estado de Alagoas, as gangues recrutavam os matadores dentro dos quadros de soldados das polícias militar e civil. Chegou-se à situação em que, dos crimes de mando praticados no estado, cerca de $80 \%$ contavam com a eficiente participação de membros das polícias" (Brasil, 1994: 62)

19. A partir da década de 1980 mesmo sob as restrições e às censuras impostas durante a ditadura militar, a imprensa alagoana irá noticiar com regularidade o envolvimento de agentes do Estado, notadamente da área da segurança pública, em atividades criminosas, sobretudo a insinuação de sua participação em grupos de extermínio. Como já foi observado por Majella, a imprensa especializada na cobertura policial deste período, para driblar os censores alagoanos, irá criar a tipificação dos chamados "crimes misteriosos". A expressão não passa de um eufemismo encontrado no intuito de evitar ção e transformação da prática de crimes em Alagoas, tomando como referência agora a institucionalização dos grupos de extermínio da região - organizações paramilitares de raízes locais, com capilaridade interestadual e de fama nacional pelos desmandos cometidos.

Sugiro que o entendimento do fenômeno da formação de grupos de extermínio no estado de Alagoas extrapola os limites da explicação tradicional que vê nessas agremiações uma mera atualização das formas de mando na região, até mesmo do sistema de pistolagem. Defendo que estas organizações inauguraram uma verdadeira "política criminal" no estado (Majella, 2006), trazendo transformações significativas para os usos e sentidos da violência na região, mas, principalmente, gerando as condições que possibilitaram o subsequente colapso do aparato da segurança pública do Estado, que culminou com as taxas estratosféricas de violência homicida verificadas no estado na primeira década do século XX e que deram a Alagoas a posição de estado mais violento da Federação, tornando-se mesmo palco privilegiado de intervenções do governo federal para o uso, como já observamos, de planos experimentais de contenção da violência urbana.

Enquanto no Sindicato do Crime a promoção das atividades ilícitas estavam relacionadas aos adversários vinculados ao agronegócio e ao sistema político, a partir da década de 1980, o incremento da participação policial junto ao sistema de pistolagem redefiniu mais uma vez as estruturas das organizações criminais no estado de Alagoas, transformando o que antes era um sindicato em uma espécie de quartel da pistolagem ${ }^{18}$. Daí emergiriam dois dos principais grupos de extermínio em Alagoas com forte atuação nas décadas de 1980 e 199019: a Gangue Fardada e os Ninjas de União. O primeiro, com forte atuação na capital do estado, mas com muitos braços espalhados pelos estados de Pernambuco, Sergipe e Bahia; o segundo, circunscrito à zona da mata alagoana, com sede na cidade de União dos Palmares.

A Gangue e os Ninjas, formada a partir dos interstícios do Sindicato do Crime, especializou-se não somente no assassinato por encomenda, mas também nos sequestros, extorsões, assaltos a banco e, sobremodo, na prática da realização de verdadeiros "expurgos" ou "faxinas sociais", executando de maneira sumária sujeitos reputados perigosos ou indesejáveis (Freitas, 1982). A presença de policiais civis e militares nestas organizações acabou por agregar a austeridade e a discrição militar típica das corporações militares à sociabilidade dos "novos" matadores; que agora evitavam ostentar a violência típica dos membros do antigo Sindicato e prezavam pela economia de palavras à hora de narrar seus envolvimentos em atividades criminosas, como pode ser observado nos vários relatos e nas transcrições de depoimentos de seus membros presos a partir do final da década de 1980. 
Sabe-se que a violência é produzida dentro de um contexto social e é nesse sentido que afirmo que a militarização da violência em Alagoas, ao se beneficiar das condições de exceção durante a ditadura militar, transformou o sistema anterior de pistolagem em algo que, se guardava relações com o passado dito arcaico e atrasado, também não se eximia de sua novidade: as atividades criminosas passavam agora a ser gerenciadas a partir do núcleo do próprio Estado, parasitárias dos próprios órgãos de segurança, o que reforçou a impunidade e a proteção dos chamados policiais-matadores. Essas transformações chegaram também ao mundo dos mandantes, como pode ser verificado no Relatório final da chamada CPI da Pistolagem no Nordeste, o qual aponta que a clientela dessas organizações não se restringia mais aos chefes políticos ou aos grandes usineiros, atendia-se agora também a comerciantes, empresários, maridos e esposas enciumados, pais de família "desonrados", vizinhos molestados e a toda sorte de gente que pudesse pagar pelos serviços (Brasil, 1994: 45). Assistiu-se, nesses tempos, a uma espécie de "democratização" da violência de mando no estado ${ }^{20}$.

Os policiais-matadores aparecerão como solucionadores de problemas privados das mais variadas naturezas e atenderão à execução dos mais diferentes desafetos. Eles seriam a "mão armada" das pessoas que tiveram um "direito violado" ou suposto como tal. Estes matadores aparecem então como espécies de vingadores, restituidores da ordem por meio de soluções violentas e estas seriam, em parte, legitimadas socialmente. Não é incomum, nos autos do Relatório final da CPl, encontrarmos na fala dos matadores um apelo à suposta legitimidade de suas ações: "nunca fiz mal a qualquer sujeito de bem". Suas vítimas iam desde mulheres e maridos traidores, passando a sujeitos acusados de velhacos, desonestos ou vagabundos, mas sobretudo, exterminaram moradores de rua, adultos egressos do sistema penitenciário e até menores saídos de unidades de internação socioeducativas. O que fica evidente do programa de violência executado por estas organizações paramilitares é que sua "justiça" não era orientada mais contra um indivíduo ou uma forma de ação violenta, mas principalmente contra o que não se julgava mais tolerável socialmente.

Neste momento de transição entre o antigo Sindicato e os grupos militarizados de extermínio, observamos uma transformação na forma de se operar a criminalização e a construção social do crime no estado de Alagoas. Enquanto nos tempos idos do Sindicato a prática do enfrentamento e da vingança entre vítimas e pistoleiros levava em conta a "transgressão" cometida pelo sujeito, pela qual ele seria "punido", a partir dos grupos de extermínio, a criminalização passou a ser direcionada sobre um tipo. A Gangue e os Ninjas deram corpo em Alagoas à constituição de um modelo seletivo de distribuição da violência, a qual recaía enfrentamentos diretos com a aparato de segurança do Estado (Majella 2006).

20. A dimensão das ações dos grupos de extermínio em Alagoas pode ser percebida a partir da multiplicação de notícias sobre a descobertas de covas, valas e cemitérios clandestinos onde as gangues "depositavam" suas vítimas, que começaram a surgir na imprensa local a partir do final da década de 1970. Dos mais de 40 cemitérios clandestinos descobertos até o final dos anos 1990 (Tribuna de Alagoas, 19 Jun. 1998; Gazeta de Alagoas, 14 Jun. 1998), seis merecem especial destaque em função do número de ossadas encontradas e da negligência no trato por parte do aparelho de segurança pública: primeiro, o chamado cemitério da Coca-Cola (Jornal de Alagoas, 02 Set. 1977), localizado nas proximidades da fábrica de refrigerantes de mesmo nome; depois, o cemitério clandestino da cidade de Pilar ( $O$ Diário, 03 Mar. 1995) e, ainda no mesmo ano, o cemitério clandestino da cidade de Pindoba (Gazeta de Alagoas 07 Jun. 1998); o cemitério do loteamento Suaçuy, no município de 
Paripueira (Gazeta de Alagoas, 20 Out. 1995) e, finalmente, os cemitérios clandestinos do bairro de Benedito Bentes e Ipioca (Gazeta de Alagoas, 12 Abr. 1998)

21. Ao refletir sobre as variações e diferenças na forma como se opera a acusação dentro do modelo clássico de incriminação e o dito modelo de sujeição criminal, Misse afirma:

"Quando é a lei que impera sobre a norma, não se pune o sujeito, mas, nele, a sua transgressão; quando, ao contrário, é a norma que dita (e reforma) a lei, é o sujeito da transgressão quem está em questão. A acusação especializase em realçar a associação do sujeito à transgressão, reificando seu caráter ou sua personalidade como homogeneamente transgressor ou não transgressor. Desparecem as nuances clássicas e o mundo é dividido em 'bons' e 'maus'” (Misse, 2008: 16). com especial atenção sobre as classes marginalizadas, homogeneamente acusadas de transgressoras, incorrigíveis e violentas ${ }^{21}$. A tônica destes grupos foi sempre a eliminação preventiva de sujeitos socialmente acusados de "incuráveis", para os quais o Estado não previa outra forma de solução que não o extermínio. Trata-se do ápice de um longo processo de controle e sujeição de tipos criminais na região que foram transformando aqueles que antes eram socialmente incriminados em potencialmente acusados e, depois, naturalmente culpados.

Conclama a teoria de constituição da civilidade burguesa que quanto menor a distância social entre os indivíduos que constituem uma tradição nacional, regional ou local, maior será a identificação excessiva entre os sujeitos e, por conseguinte, maior será o autocontrole das paixões e dos impulsos. Por outro lado, quanto maior essa distância, maior será a indiferença pelo outro e menor a normalização e a generalização das formas de autocontrole nas relações sociais (Elias, 1993; Foucault, 1974). A distância social desregulada e a sedimentação de práticas crimináveis recorrentes ao longo do tempo tornaram o estado de Alagoas o núcleo de gestação de um modelo de sujeição que vitimou por duas décadas os ditos manjados ou maloqueiros - para empregar o vocábulo próprio do dialeto policial local.

Argumento que esta exclusão socioeconômica de extensos segmentos da sociedade alagoana acompanhou também a exclusão de larga parcela desta população de acesso a direitos civis, o que reforçou sobremaneira a oferta das condições necessárias para a sujeição criminal - que encontrou nos segmentos sociais mais vulneráveis seus principais alvos. Este modelo de justiça privado orientado pela chacina, pelos crimes de mando e pela constituição de grupos de extermínio não suprimiu os procedimentos racionais-legais da justiça legal, que se desenvolveu para uns grupos e não para outros. Para além da tese da ausência de Estado ou da corrupção de costumes, o que se desenvolveu em Alagoas, a partir da década de 1980, foi um sofisticado sistema territorializado de segregação e marginalização das camadas populares operado pelos próprios agentes do Estado: neste caso, as forças policias.

Os policiais formaram o elo intermediário entre o sistema social e político hierarquizado e segregado, de um lado, e o sistema judiciário fragilizado e amorfo, de outro. Ao longo de duas décadas, foram eles que decidiram de forma discricionária sobre a vida e a morte dos sujeitos dentro dos territórios (favelas, periferias, barrancos e grotas). Os policiais transformaram-se em operadores do mando nestes espaços, gerentes de uma espécie de modelo de contenção que deveria garantir a distância social entre as classes dominantes, a classe média e a escória dos segmentos marginalizados, considerados delinquentes e perigosos. Os moradores 
destas áreas sobreviviam à própria sorte, como pode ser verificado na enxurrada de matérias jornalísticas denunciando as condições sub-humanas sob as quais famílias inteiras sobreviviam na periferia de Maceió durante a década de $1980^{22}$. Não são poucas as vezes em que os editoriais culpam o poder público e o sistema de justiça criminal pela precariedade das condições de moradia nessas áreas: faltaria de tudo, do saneamento à educação, mas faltaria sobretudo freios para conter o que o Jornal de Alagoas chamou de "uma violência generalizada, semelhante ao velho faroeste, que inclui todas as práticas de crime e onde ninguém está seguro e tudo segue envolto na impunidade"23.

O desmantelamento dos grupos de extermínio a partir da prisão de seus próceres dificultou o gerenciamento deste cordão de contenção social. A desarticulação destes grupos - como pode ser verificado no Relatório do Fórum Permanente Contra a Violência - não trouxe uma redução da violência na região. O percentual de crimes de homicídio relacionados aos grupos de extermínio decresceu ao final da década de 1990, no entanto, o percentual de ocorrência de homicídios relacionados à ação criminosa ou a conflitos interpessoais apresentou um crescimento significativo a partir de então. Mais do que um efeito perverso, o desmonte das quadrilhas de policiais-matadores trouxe à tona a inoperância do próprio Estado para responder às demandas crescentes da população por segurança e acesso à justiça.

Ao operar um modelo de justiça seletivo nas margens e arestas da cidade, os grupos de extermínio mantiveram a normalização destes espaços às custas do medo e do terror. Não pretendo afirmar que o desmonte destes grupos causou um aumento da violência homicida no estado, não é isto. Na verdade, seu desaparecimento potencializou a ocorrência dos crimes de homicídio na periferia como nunca antes, em função do acesso fácil e barato às armas de fogo. O desbaratamento destas quadrilhas demarca um momento singular no processo de acumulação social da violência em Alagoas - elas inauguram um estágio anômico de disseminação dos crimes de homicídio que coincide com o processo de falência financeira do próprio Estado, levando a situação social em Alagoas ao limite no final da década de 1990, quando o governo estadual atrasou por sete meses o pagamento do salário de 50 mil funcionários públicos, em sua grande maioria servidores das pastas da educação, saúde e segurança pública. De lá para cá, o fenômeno da violência urbana no estado de Alagoas experimentou uma espécie de espiral de crescimento, agravada ainda pela entrada do tráfico de drogas psicoativas ilícitas nas periferias da cidade a partir dos primeiros anos do novo século, com destaque para o crack.

22. Na pesquisa documental com acervo jornalístico para os anos de 1980 e 1989, identificamos a referência constante ao problema urbano da capital do estado Na virada da década de 1980, começa a multiplicar-se nos editorais jornalísticos e nos cadernos urbanos dos periódicos a menção ao déficit habitacional da cidade, às baixas condições de higiene da periferia urbana e à ocupação irregular de áreas insalubres pela população pobre vinda do interior do estado. Num editorial de 21 de janeiro de 1987 do Jornal de Alagoas, afirma-se: "O déficit de habitações populares e a falta de saneamento básico são dois dos grandes problemas da população carente de Alagoas. A cidade atualmente possui apenas $20 \%$ de ruas saneadas e o déficit habitacional supera as 30 mil unidades. São cada vez mais favelas que surgem na capital, e os favelados sofrem ao mesmo tempo com a falta de teto e esgotamento sanitário" (Jornal de Alagoas, 21 Jan. 1987).

23. "Alagoas, um estado semelhando ao velho faroeste" (Jornal das Alagoas, 03 Jan. 1988). 


\section{Considerações finais}

Neste texto, apropriei-me de partes das formulações misseanas - sem me comprometer com todo o seu esquema teórico - para construir um quadro analítico da violência urbana em Alagoas. Na sequência, argumentei que as diferentes formas de violência e autoritarismo social produzidas naquele estado ao longo dos últimos 50 anos assinalaram profundas transformações nas dinâmicas de sociabilização das comunidades urbanas e nas formas de operar o poder dentro destes territórios. Da primária estrutura das relações de clientelismo rural que armaram e municiaram capangas e jagunços em torno dos grandes proprietários de terras, passando para o fenômeno da profissionalização do sistema de pistolagem e deste para a constituição do chamado Sindicato do Crime e dos grupos militarizados de extermínio, deu-se um verdadeiro emaranhado não linear de fusões, interpenetrações e sobreposições de diversificadas formas e práticas de violência na região. Esta acumulação acompanhou ainda transformações no tocante ao entendimento do fenômeno da violência que, aos poucos, vai deixando de ser entendido como problema de ordem pessoal (vingança privada) para tornar-se um problema de Estado. Trato aqui das metamorfoses em torno da ideia de inimigo, antes e depois desse processo - num primeiro momento, o inimigo era o sujeito a quem se atribuía uma ação criminada contra um indivíduo (que legitimaria o suposto direito à vingança); num segundo momento, o inimigo tornou-se um sujeito sem rosto, sem nome, sobre o qual recairiam todas as culpas por sua suposta condição subjetiva corrompida, a qual carregaria o crime em si (são os chamados sujeitos criminais, para os quais o desvio seria uma condição e a punição sempre certa).

Em Alagoas, desenvolveu-se de forma tão interligada o poder público com o poder privado que mesmo os problemas de segurança interna e repressão ao crime, até a década de 1960, foram considerados menos como problemas de Estado e mais como querelas particulares e privadas. Nos relatórios dos chefes de polícia deste período em Maceió, pululam as queixas contra os ditos marginais, delinquentes e vagabundos que violam o sossego dos homens de bem. É sobre esses sujeitos criminais que argumento que o poder arbitrário e despótico dos grupos de extermínio inseridos nas estruturas do Estado se voltariam, décadas depois. Ao empregarem o argumento da pacificação e da limpeza social, estes grupos não somente preservaram a distância social dos tempos de outrora entre as camadas menos favorecidas e subalternas da sociedade e as classes política e economicamente privilegiadas da sociedade alagoana; abortaram ainda o processo de socialização destas comunidades, impedindo a esses grupos a obtenção de condições e posturas condizentes com a participação e a inclusão na sociedade - a contenção da impulsividade e o 
respeito às regras do jogo, cujo objetivo maior é poupar a vida alheia. Isso pode ser verificado no boom do crescimento do número de homicídios no estado a partir de 1999, quando se irradia, a partir da capital do estado, a explosão de uma violência indomesticada, por que agora inscrita no universo cotidiano, assentada em desentendimentos do dia a dia e, em sua grande maioria, sem motivações mercantis.

Abstract: Using the concepts of social accumulation of violence and criminal subjection this text aims to build a reflection about the transformations around the phenomenon of violence in the state of Alagoas. From the compilation of journalists' materials, official documents and interviews with agents of the state criminal justice system historically sought to situate the problem of violence in the region. Argue that over the last fifty years, the traditional crimes type killer rent to the "institutionalization" of extermination groups and from these to the phenomenon of proliferation of crimes of murder in the state, saw the accumulation of different violence forms and practices sedimented the creation of different dangerous types. Contrary to the analyzes that insist on interpreting the violence today exclusively as contiguity of past, argue that the explosion of homicides in the state is a peculiar event and relatively recent.

Keywords: accumulation of social, criminal subjection, violence, murders, Alagoas.

\section{Referências}

ALBUQUerQUe JR., Durval Muniz. A invenção do Nordeste e outras artes. Recife: Massagana, 1999.

BARREIRA, César. Crimes por encomenda: violência e pistolagem no cenário brasileiro. Rio de Janeiro: Relume-Dumará, 1998.

- Trilhas e atalhos do poder: conflitos sociais no sertão. Rio de Janeiro: Rio Fundo, 1992.

BEATO, Claudio. Crime e cidade. Belo Horizonte: Editora UFMG, 2012.

BECKER, Howard S. Outsiders: estudos de sociologia do desvio. Rio de Janeiro: Zahar, 2008.

BRASIL. Congresso. Câmara dos Deputados. Relatório Final da CPI da Pistolagem. Brasília: Câmara dos Deputados, 1994.

CARVALHO, Cícero Péricles. Economia popular: uma via de modernização para Alagoas. Maceió: Edufal, 2012.

. Análise da reestruturação produtiva da agroindústria sucroalcooleira alagoana. Maceió: Edufal, 2000. 
ELIAS, Norbert. O processo civilizador: formação do Estado e civilização. v. II. Rio de Janeiro: Jorge Zahar, 1993.

FOUCAULT, Michel. Vigiar e punir: nascimento da prisão. Petrópolis: Vozes, 1977.

— . A verdade e as formas jurídicas. "Série Letras e Artes". Cadernos da PUC$-R I O$, n. 16, 1974.

FREITAS, Décio. Os sindicatos da morte. Terra da Morte (suplemento). Tribuna de Alagoas. Maceió, 1982.

FÓRUM BRASILEIRO DE SEGURANÇA PÚBLICA. Anuário Brasileiro de Segurança Pública. São Paulo: FBSP, 2015.

FÓRUM PERMANENTE CONTRA A VIOLÊNCIA. Para aquém da cidadania - as várias faces da violência em Alagoas. Belo Horizonte: Missão Editora, 1992.

GOFFMAN, Erving. Estigma: notas sobre a manipulação da identidade deteriorada. Rio de Janeiro: LTC, 1988.

GOMES, Fábio G. A inserção da economia alagoana na recente dinâmica de crescimento regional. Economia Política do Desenvolvimento, v. 4, n. 10, 2011.

INSTITUTO BRASILEIRO DE GEOGRAFIA E ESTATÍSTICA. Pesquisa de orçamentos familiares (2008-2009). Rio de Janeiro: IBGE, 2010.

MACHADO DA SILVA, Luiz A. Criminalidade violenta: por uma nova perspectiva de análise". Revista de Sociologia e Política, n. 13, 1999.

Um problema na interpretação da criminalidade urbana violenta. Sociedade e Estado, v. 10, n. 2, 1995;

MAJELLA, Geraldo. Execuções sumárias e grupos de extermínio em Alagoas (19751998). Maceió: Edufal, 2006.

MATA MACHADO, Cristina. Aspectos do fenômeno do cangaço no Nordeste brasileiro. Revista de História, v. 46, n. 93, p. 139-173, Jan-Mar, 1973.

MELLO, Frederico Pernambucano de. Guerreiros do Sol: violência e banditismo no Nordeste do Brasil. São Paulo: A Girafa, 2011.

MERTON, Robert King. Sociologia: teoria e estrutura. Rio de Janeiro: Mestre Jou, 1969.

MINISTÉRIO DA EDUCAÇÃO. Anuário Brasileiro da Educação Básica. Brasília, MEC, 2017. 
MISSE, Michel (Org.). Acusados \& acusadores - estudos sobre ofensas, acusações e incriminações. Rio de Janeiro: Revan, 2008.

Malandros, marginais e vagabundos \& a acumulação social da violência no Rio de Janeiro. Tese (Doutorado em Sociologia) - Programa de Pós-Graduação em Sociologia, Instituto Universitário de Pesquisas do Rio de Janeiro (Iuperj), Universidade Cândido Mendes, Rio de Janeiro, 1999.

NASCIMENTO, Emerson O.; GAUDENCIO, Júlio Cezar. Homicídios em Alagoas: desafios e evidências empíricas. Latitude, v. 7, n. 2, p. 109-132, 2013.

RODRIGUES, José Honório. Conciliação e reforma no Brasil: um desafio histórico cultural. Rio de Janeiro: Civilização Brasileira, 1965.

SAPORI, Luís Flávio; SOARES, Gláucio Ary D. Por que cresce a violência no Brasil? Belo Horizonte: Editora PUC-Minas, 2014.

SAMPSON, R. J.; RAUDENBUSCH, S. W.; EARLS, F. Neighborhoods and violent crime: a multilevel study of collective efficacy. Science, v. 277, p. 918-924, Ago. 1997. 